\section{Ф.Г. ЯКОБИ И И. КАНТ: МЕТАКРИТИКА НИГИЛИЗМА ЧИСТОГО РАЗУМА}

\author{
КЛЮЧЕВЫЕ СЛОВА: \\ Иммануил Кант, Фридрих Генрих Якоби, \\ философия веры, критическая философия, \\ трансцендентальная философия, \\ теория познания.
}

\section{СЕРГЕЙ ВОЛЖИН}

\begin{abstract}
Кандидат философских наук, ассочиированный научный сотрудник Сочиологического института РАН Федерального научно-исследовательского сочиологического чентра Российской Академии Наук.
\end{abstract}

Адрес: ул. 7-я Красноармейская, д. 25/14, 190005, Санкт-Петербург, Россия.

E-mail: sergey.volzhin@gmail.com
В статье исследуется стратегия интерпретаиии и критики Ф. Г. Якоби кантовского критицизма, что позволяет полнее раскрыть не только специфику аргументации Якоби, направленную против односторонностей кантовской эпистемологии, но и глубже уяснить характер и структуру самого аргументативного базиса теоретической философии И. Канта, а также прояснить внутренние противоречия кантовской модели трансиендентальной философии.

В публикуемом сочинении «О предприятии критицизма привести разум к рассудку и дать филособии вообще новое направление» (1801) Якоби стремится раскрыть все следствия тех противоречий, которые возникают в теории познания Канта вследствие неопределенности статуса веши-в-себе. Якоби доказывает, что в Критике чистого разума, которая должна объяснить возможность синтетических суждений а priori, Кант не исследует возможность антитезиса а priori: многообразное, подлежащее синтезу, лишь эмпирически предпосылается Кантом. Анализ теории познания Канта приводит Якоби к тезису: разум сводится Кантом к рассудку, соотносящемуся через воображение с чувственностью, которая зависит от воображения как способности созериания а priori. Продуктивная и репродуктивная функиии воображения должны у Канта обеспечивать конституирование объекта познания и воспроизводство его как представления. Но поскольку в «Критике чистого разума» Кант не указывает условий саморазличения чистых пространства, времени и сознания, то Якоби констатирует, что с предпосылкой о чистом как непрерывном, равном самому себе и неопределенном невозможно достичь чистого различия, чистого множества, а от них прийти к определенности: вопрос о возможности априорных синтетических суждений неразрешим, так как необъяснима сама возможность синтеза. Согласно Якоби, теория познания Канта могла бь объяснить возможность познания тишь в одном случае: исходя из деятельности силь воображения в генезисе ее от слепой (чувственной) к зрячей (интеллектуальной) способности души; но выявленные Якоби внутренние противоречия основ кантовской теории познания приводят его к выводу: нигилизм и солипсизм являются неизбежными следствиями этой теории. В своей аргументаиии в этой работе Якоби одним из первых указал на фундаментальньй характер понятия времени в кантовской системе. 
$\prod$ убликуемое впервые на русском языке сочинение Фридриха Генриха Якоби «О предприятии критицизма привести разум к рассудку и дать философии вообще новое направление» («Über das Unternehmen des Kritizismus die Vernunft zu Verstande zu bringen und der Philosophie überhaupt eine neue Absicht zu geben») (1801), являет собой, пожалуй, одно из важнейших «антикантовских» сочинений рубежа XVIII и XIX вв. В данном произведении представлены в наиболее развернутой форме (не исключающей, впрочем, порой и определенную резкость) почти все основные аргументы Якоби против критической философии Канта, сформулированные в ходе длившейся более десяти лет полемики. Именно на эту работу Якоби опирались Карл Леонард Рейнгольд, Шеллинг и Гегель в спорах о «рациональном реализме», «трансцендентальной философии» и «спекулятивной философии», разгоревшихся на пороге XIX в.

Следует сказать несколько слов об истории создания и публикации данной работы Якоби. В конце 80-х гг. XVIII в. Якоби начал подготовительные работы к задуманному им обширному сочинению, посвященному разбору кантовской философии; Якоби надеялся написать свой Opus Magnum или «Hauptwerk» об истине («Was ist Wahrheit?»). Следы подготовки к этому, так и оставшемуся в виде плана, сочинению заметны по весьма характерной манере проработки изданий кантовских текстов из личной библиотеки Якоби ${ }^{1}$. Сочинение «Что есть истина?» («Was ist Wahrheit?»)2 Якоби планировал в 1786-1787 гг. поместить вслед за приложением «О трансцендентальном идеализме» $(1786)^{3}$ в качестве основного приложения к публикации своего сочинения "Давид Юм о вере, или разговор об идеализме и реализме» (1787) 4 . Сохранившимся свидетельством этого плана является весьма своеобразный по стилю и форме изложения фрагмент о кантовской философии, который Якоби написал в 1791 г., - «Послание о кантовской философии» («Epistel über die Kantische Philosophie») (1791) 5 .

1 См. об этом подробнее: Ortlieb 2007, 252-264.

2 См. об этом подробнее в приложении ко 2 тому современного критического издания сочинений Якоби (Jacobi Werkausgabe) JWA 2.2: Jacobi 2004b, 482 («Die Liste zu Über das Unternehmen des Kritizismus»). См. также: Jaeschke, Arndt 2012, 352.

3 Cм. JWA 2.1: Jacobi 2004a, 103-112. Рус. пер.: Гаман, Якоби 2006, 198-205.

4 Cм. JWA 2.1: Jacobi 2004a, 9-112. Рус. пер.: Гаман, Якоби 2006, 91-169.

5 Это сочинение, адресованное другу Якоби, Маттиасу Клаудиусу, немецкому поэту, писателю и издателю, было написано в ответ на многократные просьбы последнего дать общую характеристику кантовской философии. Поэтому «Послание» должно было отвечать двум требованиям: во-первых, оно должно было обеспечить доступ к пониманию критической философии для начинающего, и, во-вторых, иметь характер рецензии с общими выводами. Этими задачами обусловлен в том числе и стиль изложения этого сочинения Якоби. Менее всего он стремился следовать в своем разборе тональности изложения Канта, отсюда характерный иронический и подчас шутливый тон обсуждения критической философии. «Послание» опубликовано относительно недавно - в 2004 г., см. JWA 2.1: Jacobi 2004a, 123-161. 
Другой важной предварительной разработкой, касающейся преимущественно практической философии Канта, стал фрагмент, прочитанный Якоби Карлу Леонарду Рейнгольду при их личной встрече в 1800 г. Рейнгольд, как об этом сообщает сам Якоби в предисловии к «О предприятии критицизма», пожелал опубликовать незавершенный набросок Якоби в неизмененном виде в своих «Материалах» («Beitäge»), философском журнале, который издавал Рейнгольд. Якоби, со своей стороны, предложил Рейнгольду опубликовать не фрагмент, а его переработанную и даже - ради большей связности сокращенную версию, однако, приступив к выполнению задуманного, пришел к необходимости основательного изменения изначального плана всего полемического сочинения о кантовской философии. В ходе работы над новым текстом Якоби делает обширные выписки, приводит ссылки и цитаты из кантовских работ, сопровождает их комментариями, местами использует даже своеобразный «монтаж цитат», дабы побудить читателя «прочитать и удержать [в мысли] все важнейшие положения» всех трех Критик «равным образом», чтобы "верно схватить необходимый облик их взаимосвязанного содержания», "облик целой системы» (Jacobi 1816, 62-636), - все это создает тот базис, на котором Якоби филигранно выстраивает положения своей «метакритики». Здесь нет нужды подробно останавливаться на всех обстоятельствах работы Якоби над его сочинением, поскольку как сами эти обстоятельства, так и связанные с ними корректировки текста достаточно подробно разъяснены самим Якоби в предисловии к «О предприятии критицизма». Вместе с тем следует обратить внимание читателя на одну важную структурную особенность всего сочинения: первая его часть, касающаяся преимущественно анализа теоретических оснований кантовского критицизма - «Критики чистого разума», написана самим Якоби, а вторая - относящаяся как к теоретической, так и к практической философии Канта - другом Якоби, Фридрихом Кёппеном, подготовившим ее по заранее разработанному Якоби плану, опираясь на выписки из записной книжки (Vorbereitungs-Kladde) Якоби, которые тот ему предоставил ${ }^{7}$.

6 «О предприятии критицизма» цитируется нами в переводе на русский язык по первому собранию сочинений Якоби, опубликованному в Лейпциге в 1812-1825 гг. См. также JWA 2.1: Jacobi 2004a, 259-330.

7 В предисловии к «О предприятии критицизма» Якоби следующим образом разъясняет причину, по которой он был вынужден обратиться за помощью к Кёппену: «И вот, я подверг скрупулезной проверке этот возникший вопреки моей воле расширенный проект: я упорядочил его окончание, тщательно измерил свой путь, который мне оставалось пройти до цели, определил и сосчитал число моих путевых дней и запасся с избытком всем необходимым, дабы во время самого путешествия не возникало никакой задержки. И вот, таким образом подготовленный, снаряженный и обеспеченный, я принялся за продолжение моего труда, и он продвигался вперед, как то и было нужно. Вот уже я преодолел самую тяжелую часть пути: впереди больше не осталось участков, представляющих собственно серьезную опасность, оставался лишь один непроходимый, но все же уже более чем наполовину проторенный отрезок, $и$ - вот я уже на удобной дороге, которая ведет меня по красивым и даже плодородным местностям к желанной цели; но именно 
Эти подготовительные выписки-заметки из записных книжек являются еще одним крайне важным источником для понимания истории создания публикуемого сочинения Якоби. Он разработал собственную систему «приближения», освоения и усвоения изучаемых им текстов, включающую работу с материалом изданий (подчеркивания, пометки, использование цветных карандашей и чернил, выписки отдельных понятий на полях, ремарки поверх текста, комментарии), работу по выстраиванию каркаса цитат в записных книжках (собственноручные выписки цитат, монтаж цитат, вклейки и/или вкладки новых страниц), комментирование (нередко «в режиме диалога»), «наслаивание» ремарок и комментариев, выстраивание режимов смысловых взаимодействий отдельных слоев комментариев. Эти ценнейшие "Gedankenbuecher» или "Kladden», как их называл сам Якоби, были исследованы Петером Паулем Шнейдером и большей частью опубликованы ${ }^{8}$. Корнелия Ортлиб указывает на 13 ранее сохранившихся тетрадей, две из которых были утрачены. Для того чтобы оценить только объемы подготовительных работ Якоби, можно указать лишь на приблизительное количество страниц утраченных тетрадей: речь может идти примерно о 500 (!) страницах ${ }^{9}$. Частично опубликованные записные книжки Якоби представляют огромную ценность не только для якобиведения и кантоведения, но и для понимания многих линий развития до- и послекантовской философии. «Gedankenbuecher» или «Kladden» Якоби позволяют заглянуть во внутреннюю «лабораторию духа» мыслителя, дают возможность понять не только главные мотивы его “метакритики» рационального Просвещения, но и то, как именно, в каком направлении и с какой интенсивностью двигалась его мысль, на что в особенности он обращал свое внимание в ходе усвоения в нашем случае - ключевых положений всех трех Критик Канта, и прежде всего - «Критики чистого разума», продумывая и истолковывая внутреннюю взаимосвязь всех частей критического учения.

Публикация наконец завершенного сочинения Якоби «О предприятии критицизма» - после многочисленных задержек и проволочек - состоялась

в этот самый момент печальное событие принудило меня внезапно остановиться. В течение целых трех недель я испытывал головокружение и сопряженную с ним слабость зрения, почти полностью исключавшие для меня всякую возможность читать и писать. В течение всего этого времени изменения моего состояния неоднократно приводили лишь к ухудшению, вместо чаемого улучшения. Обессилевший от этой болезни, я, в конце концов, и вовсе потерял всякую надежду. И тут у меня родилась мысль обратиться с просьбой и предложением к моему другу, Кёппену из Любека, который часто радовал меня своими посещениями: не пожелает ли он, действуя в соответствии с моим планом и опираясь на мои подготовительные выписки из записной книжки (Vorbereitungs-Kladde) и приложения к ним, - каковые я мог бы расширить, - завершить работу над прерванной моей болезнью статьей? - Он согласился на это из подлинной сердечной дружбы: он надеялся облегчить мое выздоровление тем, что снимет с моей души груз этого дела, знаменующего столь несчастливую эпоху в моей жизни, а успех [дела] доказал, что он, по крайней мере, в этом не совсем обманулся» (Jacobi 1816, 63-64).

8 См.: Schneider 1986.

9 См. об этом подробнее: Ortlieb 2007, 263-264. 
только осенью 1801 г.: работа увидела свет в третьей тетради гамбургских «Материалов» Рейнгольда (Jacobi 1801), и вышла практически одновременно с сочинением Гегеля «О различии систем философии Фихте и Шеллинга» («Differenz des Fichte'schen und Schelling'schen Systems der Philosophie») (1801). Якоби, как впрочем и сам издатель его труда - Рейнгольд, вполне отдавал себе отчет в несвоевременности этой публикации, поскольку основная тема сочинения Якоби - прояснение внутреннего характера кантовской философии и обсуждение главных ее итогов - была на тот момент в основном уже исчерпана в ходе широкой дискуссии о критицизме между главными представителями основных направлений немецкой философии. Как отмечают Вальтер Йешке и Андреас Арндт, сам Якоби в ту пору в одном из своих писем к Рейнгольду говорил, что он, “целясь своим сочинением в Канта, надеется также "задеть" и Фихте» (Jaeschke, Arndt 2012, 352), поскольку именно в Наукоучении Фихте Якоби видел наиболее последовательно осуществленную, законченную и совершенную форму той философии, начало которой было положено критическим проектом Канта. При этом сам Якоби - в указанной переписке - признается, что «возраст и силы» не позволяют ему должным образом «атаковать» философские системы Фихте и Шеллинга, поскольку для этого ему нужно было бы проработать их философские работы по крайней мере столь же основательно, как это было сделано им в отношении Канта и его учения (ibid.). Рейнгольд, который полагал, что Якоби в своем сочинении недостаточно уделил внимание собственно трансцендентальному идеализму Канта, в качестве издателя - и с большой вероятностью без ведома Якоби - добавил в публикуемый им текст «О предприятии критицизма» массив собственных примечаний, которые были позднее, уже при подготовке публикации собраний сочинений Якоби, удалены. Тем не менее добавленные Рейнгольдом примечания сыграли свою роль, поскольку не в последнюю очередь благодаря им Якоби оказался втянут в полемику между Фихте и Шеллингом (ibid., 353).

Несвоевременность первой публикации «О предприятии критицизма», а также кажущаяся на первый взгляд «неактуальность» темы этого сочинения Якоби в период, когда уже отшумели главные баталии о кантовском критицизме и обсуждались более «важные и насущные» вопросы о путях дальнейшего развития философии (и отнюдь не только трансцендентализма), заставляют задаться вопросом: в чем заключается непреходящая ценность этого сочинения? - Для того чтобы увидеть, что это, пожалуй, ключевое «антикантовское» сочинение Якоби при всей несвоевременности его первого выхода в свет тем не менее заключает в себе нечто весьма значимое и «актуальное» до сих пор (как для понимания исторического развития всего немецкого идеализма, так и для понимания характера многих последующих дискуссий о судьбе философии), следует принять во внимание одно открытие, которое Якоби сделал еще в 80-е годы XVIII в. Якоби в ходе инициированного им «спора о пантеизме» (в котором приняли участие почти все наиболее значимые умы немецкого Просвещения, не исключая и самого Канта) подметил одну существенную 
особенность метафизики Спинозы, систему которого Якоби считал совершенной и законченной формой рационализма Нового времени ${ }^{10}$. В примечательном во многих отношениях втором издании «Писем к М. Мендельсону об учении Спинозы» (1789) ${ }^{11}$, имеется Дополнение VII ${ }^{12}$, в котором Якоби раскрывает своего рода тайну ${ }^{13}$ метафизики Единства Спинозы:

...Спинозе удалось смешать между собою понятия причины и основания, вследствие чего понятие причины утратило свойственный ему смысл и превратилось в нечто исключительно логическое. Это превращение я уже освещал в другом месте и, как мне кажется, доступно там показал, что понятие причины в силу своего отличия от понятия основания есть опытное понятие, которым мы обладаем благодаря тому, что сознаем причинность (Causalität) и пассивность, свойственные нашему Я, и что вывести это понятие из исключительно идеального понятия основания представляется делом столь же мало возможным, сколь и свести их к полному отождествлению и неразличимости одного от другого.

Соединение обоих этих понятий, каким оно выступает в положении о достаточном основании, вовсе не является чем-то недопустимым, если, однако, при этом ни на единый миг не забывать, что́ именно лежит в основании каждого из них в отдельности, образуя саму возможность того и другого. Тогда положение основания окажется таким: все зависимое зависит от чего-то (Alles Abhänige ist von Etwas abhängig); а положение причины гласит: все то, что делается, должно делаться благодаря чему-то (Alles was getan wird, muß durch Etwas getan werden). В случае с положением основания, словом «зависит» уже указывается на нечто такое, от чего существует зависимость; то же самое происходит и в случае с положением причины: слово «делается» уже предполагает наличие чего-то такого, что́ полагает само деяние. Оба эти положения - суть положения тождества, а потому они обладают всеобщей аподиктической действенностью. Соединяются же они посредством следующего положения: «все обусловленное должно иметь свою причину», которое также является положением тождества, а, следовательно, оно столь же необходимо и всеобще, как и первые два.

Упуская из виду это существенное различие обоих понятий, а также то основание, на котором зиждется их различие, - окажется позволительным подставлять одно на место другого и выдавать одно понятие за другое, с успехом делая вывод, будто вещи могут возникать без самого их возникновения, изменяться, но при этом не претерпевать самого изменения, могут выступать друг за другом или друг перед другом и при этом не находиться в определенной последовательности. (Следовательно, causa sui (причина самой себя) обладает

10 Якоби, как известно, в «моральном пантеизме» Фихте усматривал «антипода-близнеца» натуралистического пантеизма Спинозы, а Наукоучение понимал не иначе как «обратный спинозизм» (Якоби 2006г, 210). Подробнее см. «Письмо Ф. Г. Якоби к И. Г. Фихте» (1799): Jacobi 2004a, 191-258 (JWA 2.1); рус. пер.: Гаман, Якоби 2006, 206-264.

11 CM. JWA 1.1: Jacobi 1998, 1-268.

12 Рус. пер.: Гаман, Якоби 2006, 183-197.

13 Подробнее об этом см.: Sandklauen 2000, 64-77. 
наличным бытием. Из аподиктического положения: «Все должно иметь свою причину», может быть строго доказано, "что не все может иметь свою причину». Вот поэтому и была изобретена causa sui, которой с необходимостью присущ также и Effectus sui.)

Если же всегда держать перед глазами [одно лишь] существенное различие обоих понятий, то вместе с понятием причины, полагающим необходимость понятия действия, нам придется неподвижно застыть во времени: ибо действие, совершающееся вне времени, суть нелепость. И даже идеализм со всем своим искусством не может здесь ничем помочь: ведь он способен дать нам лишь краткую отсрочку от неотвратимого застывания в неподвижности (Гаман, Якоби 2006, 189-190).

Что поднятый Якоби вопрос об отношении основания и причины в философии отнюдь не праздный, подтверждает хотя бы то внимание, которое этой проблеме уделяли уже Шопенгауэр и Кассирер ${ }^{14}$. Применительно к аргументации Якоби против критицизма Канта указанное выше открытие Якоби проявляется таким образом, что не в последнюю очередь именно та самая ясность усмотрения Якоби, которая позволила ему разглядеть «тайну метафизики Спинозы ", позволила также вскрыть источник двойственности и оснований, и ключевых выводов теоретической философии Канта. Якоби и Кант действуют сходно: Кант подвергает обследованию разум, Якоби «метакритически» обследует «критический» разум; если критическое предприятие Канта (в теоретической сфере) стремится «показать разуму» источник и природу его диалектичности, то Якоби - как справедливо подметила Биргит Сандклауэн - исследует вопрос о том, естественно или же искусственно происхождение заблуждения, в которое впадает разум относительно себя самого ${ }^{15}$.

Каковы же результаты «обследования» критического разума, полученные Якоби? - Прежде всего, в своем небольшом по объему, но исключительно важном сочинении «О трансцендентальном идеализме», Якоби первым подметил непоследовательность в «предполагаемой по умолчанию» Кантом причинности при аффицировании чувственности вещами-в-себе. Кант не признает отождествления основания и причины, принятого в непосредственно предшествующей критицизму метафизике, и тем не менее парадокс вневременного основания как причины воздействия сохраняется на уровне зависимости трансцендентального понятия чувственности от неопределенного представления о вещи-в-себе. Якоби находит затруднение в самом статусе вещи-в-себе:

Ведь, согласно общему словоупотреблению, под предметом следовало бы разуметь вещь, которая находилась бы в трансцендентальном смысле вне нас, - а как возможно прийти в кантовской философии к такой вещи? Не путем ли того рассуждения, что при представлениях, называемых нами явлениями, мы чувствуем себя пассивными? Ощущение же пассивности или состояние

14 Ср., например: Schopenhauer 1962, 12-56; Cassirer 1991, 17-32.

15 Подробнее об этом см.: Sandklauen 2000, 133-138. 
претерпевания есть всего лишь половина всего состояния в целом, и по одной лишь этой половине оно немыслимо. Поэтому и в данном случае следовало бы также твердо требовать немыслимости такого состояния на основе одной лишь этой половины. Иначе получилось бы, будто мы ощущали в трансцендентальном смысле причину и действие и в силу этих ощущений смогли заключать к вещам вне нас и к их необходимым взаимоотношениям в трансцендентальном смысле. Но, так как это привело бы к крушению всего трансцендентального идеализма, к утрате им своего смысла и возможности всякого применения, то его последователь должен, по-видимому, отвергнуть саму эту предпосылку, отказавшись даже от вероятности допущения того, будто вне нас в трансцендентальном смысле существуют какие-то вещи, стоящие к нам в каком-то отношении и доступные некоему восприятию с нашей стороны. Но, допуская такую вероятность, желая даже хоть сколько-нибудь отдаленно только поверить в существование таких вещей, он необходимо должен будет выйти из трансцендентального идеализма и будет принужден впасть в поистине неразрешимые противоречия с самим собой (Гаман, Якоби 2006, 204-205).

Вопрос о статусе реального в кантовской теоретической философии, и прежде всего - вопрос о реальности вещей вне нас, Якоби увязывает в своей статье «О трансцендентальном идеализме» с вопросом об их причинности: если вне нас нет ничего реального и вещь в себе не причина, аффицирующая нашу чувственность, то и сам факт нашей чувственности в кантовской трактовке становится проблематичным, а вместе с ним проблематичной оказывается и вся кантовская конструкция теории способностей познания; если же вне нас есть нечто реальное, которое все-таки выступает причиной аффицирования нашей чувственности, то рушится сама предпосылка, при которой возможно «вступить» внутрь «Критики чистого разума». Отсюда знаменитый парадокс Якоби:

...сколь ни противоречит духу кантовской философии допущение предметов, воздействующих на чувства и вызывающих таким образом представления, то все же не совсем ясно, каким образом без этого предположения философия Канта могла бы найти впервые доступ к себе самой и прийти к какому бы то ни было изложению своего учения. Ибо слово чувственность лишается тотчас же всякого значения, если не понимать под ним особой реальной сферы между одним реальным и другим реальным - то есть действительного посредствующего звена от одного нечто к другому, и если в понятии чувственности не предполагать уже содержащимися понятия внеположности и связанности, самодеятельности и претерпевания, причинности и зависимости как реальных и объективных определений; и притом содержащимися в нем таким образом, что абсолютная всеобщность и необходимость этих понятий дается одновременно с понятием чувственности как предшествующая этому понятию предпосылка. Должен сознаться, что это обстоятельство явилось мне сильной помехой при моем изучении кантовской философии, так что несколько лет подряд я должен был снова и снова приниматься за чтение «Критики чистого разума», ибо я оказывался в непрерывном замешательстве, видя, что без этой 
предпосылки я не могу войти в систему, а вместе с такой предпосылкой не могу в этой системе оставаться.

Оставаться в ней с этой предпосылкой совершенно невозможно, поскольку в основе ее лежит убеждение в объективной значимости нашего восприятия предметов вне нас как вещей в себе, а не как одних лишь субъективных явлений, также как и убеждение в объективной значимости наших представлений о необходимых отношениях предметов друг к другу, их существенных отношениях как объективных, реальных определениях. Эти утверждения никоим образом невозможно увязать с кантовской философией, ибо последняя ставит себе целью показать прямо противоположное, а именно, что как предметы, так и их взаимоотношения суть только лишь нечто субъективное, что они суть простые определения нашего собственного Я, которых вовсе не существует вне нас. Ибо, если кантовская теория и могла бы еще допустить, что этим только субъективным сущностям, представляющим собою лишь определения нашего собственного существа, соответствует некая трансцендентальная причина, то все же остается сокрытым в глубочайшем мраке, где же находится эта причина и в какого рода отношении стоит она к действию (Гаман, Якоби 2006, 202-203).

Якоби оказался первым критиком кантовского учения, который признал идеалистический характер «Критики чистого разума» и требовал последовательного осуществления идеализма в этом учении. Однако опровержение Кантом идеализма во втором издании Первой Критики обнаружили не просто колебания ее автора в том, чтобы продолжить движение в этом направлении, но и нечто гораздо большее: Якоби мог расценивать такой шаг Канта лишь как попятное движение в развитии всего проекта критической философии, что и побудило Якоби высказать в статье «О трансцендентальном идеализме» замеченную им трудность при сравнении текстов первого и второго изданий «Критики чистого разума». Впоследствии, как известно, Шопенгауэр хвалился тем, будто он первый заметил существенную разницу текстов первых двух изданий Первой Критики, хотя первым, кто указал на эти различия, был именно Якоби.

Разрешение парадокса кантовского трансцендентализма Якоби видел лишь в одном направлении: в том, которое, по его глубокому убеждению, будучи последовательно осуществленным, неотвратимо ведет к Фихте и его Наукоучению. Якоби видит отчетливо, что Кант, желая уклониться от односторонностей как догматического материализма, так и догматического идеализма, становится на путь, который ведет от наиболее чистого - в догматическом выражении - монизма Спинозы к монизму трансцендентального типа. При этом Якоби не дает себя подкупить заявлениями о высшем «срединном пути» идеал-реализма, в направлении которого - и это хорошо видит и понимает Якоби - главные шаги делает уже сам Кант при разработке плана трансцендентальной философии, за ним идут - Рейнгольд, Сигизмунд Бек и Фихте, а еще далее пойдут - Шеллинг и Гегель. Кант же, желая избежать односторонностей эмпиризма и идеализма попадает, по мнению Якоби, в другую, не 
менее опасную, ловушку, грозящую рассогласованием оснований его системы. Уже в предисловии к «О предприятии критицизма» Якоби как раз и диагностирует внутреннюю несогласованность кантовской системы, но именно в этом ее качестве он усматривает характерное в ней и даже ее определенное «преимущество»:

...осуществление [кантовской критики разума] должно было оказаться столь дедалическим, что столь же трудно показать ее действительные противоречия, сколь и развеять у мнимых видимость их противоречивости; столь же тяжело защищать правильное этой системы, сколь и опровергнуть неправильное в ней. Именно этой амальгамой искусственной двусмысленности она, преимущественно, и обязана благосклонности ее приема и многочисленной толпой неизменно верных ей друзей. Ее основной недуг, ее хамелеонов цвет в том, что она, будучи наполовину априорной, наполовину эмпиричной, должна парить посередине между идеализмом и эмпиризмом - а это весьма по вкусу широкой публике. Что-то в человеке противится абсолютному учению о субъективности, этому совершенному идеализму; напротив, человек легко уступает, если сохраняется хотя бы только название объективного (Jacobi 1816, 76-77).

В «О предприятии критицизма» Якоби стремится в полной мере раскрыть все следствия того противоречия, в которое, как он полагает, неизбежно впадает Кант вследствие неопределенности статуса вещи-в-себе. Кант в «Критике чистого разума» видит свою задачу в объяснении возможности априорных синтетических суждений, однако это только половина задачи. Вот наиболее сжатая формулировка Якоби всей проблемы Канта: «если должен быть объяснен синтез a priori, то вместе с тем должен быть объяснен также и чистый антитезис» (ibid., 79), т. е. действительность условий всякого априорного синтеза. Но в Первой Критике Якоби не усматривает даже сколько-нибудь отдаленного предчувствия этой потребности. Наоборот, он отмечает, что «Кант говорит о синтезе однородного без предшествующего [ему] антитезиса так, как будто возможность первого не подлежит ни малейшему сомнению» (ibid., 79-80). А это, в свою очередь, и позволяет Якоби утверждать, что многообразное для априорного синтеза «эмпирически предпосылается» (ibid., 80) Кантом: ведь многообразное и для априорного синтеза почему-то должно было оставаться у Канта тем же самым эмпирическим «многообразным» даже и тогда, когда Кант нам предписывает полностью абстрагироваться от всего эмпирического. Именно в этой двусмысленности, как надеется доказать Якоби, и коренится самообман создателя Критики: «вот эта-то обманывающая саму себя предпосылка как раз и обманула создателя системы вместе с его системой, и предпосылка эта проявилась в самых разных обличьях во всех отдельных ответвлениях системы» (ibid.).

Если строго следовать букве Критики, то в кантовской конструкции теории познания разум не может признавать никакого другого объекта познания, кроме объекта, признаваемого рассудком, - поэтому Якоби набрасывает довольно простую схему: 
разум должен отсылать единственно и исключительно к рассудку, который, со своей стороны, должен отсылать нас к чувственности, а она, вместе с рассудком, должна отсылать нас к силе воображения, которая должна отсылать нас, наконец, к некому = $X$ субъекта $и$ некоему $=X$ объекта, которые представляют собой последнее в познавательной способности, но которые, однако, ни субъективно, ни объективно еще не могут обосновать саму познавательную способность (ibid., 87).

Рассудок может давать знание, лишь опираясь на чувственность, которая не имеет перед собою ничего, кроме своих априорных форм; т. е. разум - заключает Якоби - сводится Кантом к рассудку, который через воображение соотносится с чувственностью, каковая, в свою очередь, зависит от воображения, взятого в качестве «полноценной способности созерцаний а priori» (ibid., 92), которая, как полагает Якоби, у Канта должна и создавать объект, и воспроизводить его как представление.

Но объект познания, как доказывает Якоби, не может быть создан подобным образом: согласно Якоби, в «Критике чистого разума» Канта совершенно отсутствуют те условия, из которых становилось бы понятно саморазличение чистого пространства, времени и сознания:

Пусть пространство - одно, время - одно, сознание - одно: точно так, как вы того требуете. Поведайте же, как у вас одно из этих трех "одних» в самом себе чисто омногообразивается (vermannichfaltiget), т. е. как вы достигаете чистого единства и чистого множества, условий чистого синтеза? Ведь ни одно из этих трех "одних» не есть только в себе и для себя самого единство, но каждое из них есть лишь, так сказать, одно и не другое (Eines und kein Anderes), одно-слож-ность (eine Ein-Fach-Heit), одно-и-то-же-ство (eine Einer-Lei-Heit), один-одна-одно-и-то-же-ство (eine Der-Die-Das-Selbig-Keit) без различенных общностей мужского, женского и среднего рода (ohne Derheit, Dieheit, Dasheit) (ibid., 113-114).

Якоби недоумевает, как можно с предпосылкой о чистом единстве как непрерывном, равном самому себе и неопределенном достичь чистого же различия, чистого множества, а от этих чистых прийти к какой-либо определенности; как вообще при этом можно прийти к решению главного вопроса Критики разума о возможности априорных синтетических суждений, если непонятно, как прийти к понятию синтеза вообще. Отсюда вывод Якоби: если разум покоится на рассудке, рассудок - на силе воображения, сила воображения - на чувственности, чувственность - снова на силе воображения как на способности априорных созерцаний, то эта последняя - опирается лишь на саму себя, и вне ее нет никакой другой опоры; иными словами - вне ее есть только ничто. Поэтому Якоби усматривает в теории способностей познания Канта всего лишь обновленную версию старой мифологической конструкции: мир, несомый слонами, которые стоят на черепахе; сила воображения у Канта и представляет, согласно Якоби, «подлинную черепаху», «абсолютное основание, сущностное во всех существах»: 
Из себя чисто априорно она производит саму себя, и как сама возможность всего возможного (производящее производства, выражающее себя в явлении как вмешательство (ein Eingreifen), аппрегендирование (Apprehendieren)) она производит не только лишь то, что возможно, но также и то, что - может быть! - не возможно. Довольно: перед нею ничего не может быть, а вот то, что после нее, - есть только посредством нее, в ней и из нее (ibid., 116).

Иными словами, теория познания Канта, согласно Якоби, могла бы объяснить познание и саму его возможность лишь исходя из деятельности силы воображения в ее развитии от слепой к зрячей способности души; однако показанные Якоби внутренние противоречия фундаментальных основ кантовской теории познания не позволяют ему сделать никакого иного вывода, кроме следующего: необходимыми следствиями этой теории являются нигилизм и солипсизм. При этом именно Якоби одним из первых - если вообще не первым - указал в этой своей работе не только на структурообразующий для всей кантовской системы характер силы воображения, но и на фундаментальный характер понятия времени как производной от этой силы чистой сущности и условия многообразия всего конечного бытия:

...если уж обязательно должно быть и быть априорно возможным, что в наши три равно чистые, равно простые и равно бесконечные едино-сущия (Einheits-Wesen) [пространства, времени и единства сознания] проникла конечность, и причем (NB!) как иная столь же чистая сущность, с тем чтобы перед нами возникло чистое многообразное, чего мы столь совершенно и полностью лишены, но в чем мы ведь прежде всего так нуждаемся, - то в дело тогда должно было бы вмешаться посредником нечто совершенно неожиданное.

И в самом деле - это неожиданное и вмешивается сюда посредником. Смотри-ка! Вот является чудесным образом шествующая сущность, называемая трансцендентальной силой воображения, и направляется в самую гущу чистых представлений, дабы их пробежать (durchlaufen). Она вступает одновременно в основание единства вне нас - в пространство, и в основание единства внутри нас - в чистое сознание, и поскольку она вошла в них шагая, то на своих двух ногах - одновременно продуктивных и репродуктивных, одновременно антитетических и синтетических - она принесла с собою не только для всего повсюду начало и конец, но также и постоянное продвижение вперед (!), сукцессивное время, которое - как общее обоим противоположным основаниям единства - внешнему и внутреннему, но ни в коем случае ни одному, ни другому не свойственное, средство изначального антитезиса и изначального синтеза - сводит их воедино и в человеческой душе учиняет и открывает триединство, во имя коего заклинаются основоположения (Grundsätze).

Я надеюсь, что вы [Иммануил Кант] меня не упрекнете в том, что о трансцендентальной силе воображения я говорю не так, как говорите вы: что она вступает в пространство и время, - но: что она вступает в пространство и в изначальное сознание. Ибо, выразив так вашу мысль, я предполагаю, что под словом «время» вы не можете разуметь уже сукцессивное время: ведь последнее впервые возникает, впервые порождается благодаря шествованию 
силы воображения, она приносит его вместе с собой, но ни в коем случае не может его найти уже наличным. Поэтому под словом «время» вы можете понимать здесь лишь время до всякого времени, и, быть может, под этим временем до всякого времени, в свою очередь, вы можете понимать ни что иное, как еще непрерывное и единственно лишь через вступление [в него] трансцендентальной силы воображения прерываемое (allein unterbrechbare) - само чистое сознание. Что то время, которое вы называете “само время" (die Zeit selbst), - я имею в виду чистое, не сукцессивное, всякому опыту предшествующее время, то время, которое есть единство всех времен и их субстрат, что это время, которое не изображает еще никакой иной modum, кроме упорствования (modum der Beharrlichkeit), что оно само не есть протекающее, но внутренне застывшеe (stillstehende) время - как оно самим учителем оного однажды и было названо, - в котором все протекает: чем же еще оно должно быть в душе, если не охватывающим всё чистым сознанием, чем-то столь же не доступным созерцанию, сколь и мышлению? (ibid., 135-138)

Завершая на столь высокой ноте это предисловие, вместе с тем следует отметить, что полемическое отношение Якоби к критицизму и трансцендентализму не ограничилось лишь его «метакритикой» философии Канта. Линия «метакритики», которую Якоби начал с «Критики чистого разума» Канта, была продолжена им в отношении Наукоучения Фихте: именно Якоби в своем Письме к Фихте 1799 г. показал творцу Наукоучения весь масштаб и всю глубину проблемы реальности нравственной цели человеческого бытия; а что критика Якоби не оказалась пустым звуком для гениального создателя Наукоучения, хорошо известно по разработке темы о «назначении человека» в одноименном сочинении, где Фихте едва ли не дословно воспроизвел ключевые аргументы Якоби из вышеупомянутого послания Письма к Фихте. Хорошо известно также и то значение, которое имела для философии позднего Шеллинга проблема реальности Откровения - проблема, масштаб которой был осознан Шеллингом не столько вопреки, сколько благодаря философской позиции Якоби.

Вниманию читателя предлагается первая часть сочинения «О предприятии критицизма», т. е. часть, написанная самим Якоби. В настоящее время готовится перевод второй части работы - написанной Кёппеном. Перевод первой части сочинения «О предприятии критицизма» выполнен по изданию: Friedrich Heinrich Jacobi's Werke. Bd. III. Leipzig: Bei Gerhard Fleischer, 1816. S. 59-158. Издания сочинений Канта, использовавшиеся Якоби для цитирования и ссылок, идентифицированы редактором - О. Н. Ноговициным, ему же принадлежат отдельные примечания к переводу. Постраничные сноски в тексте перевода соответствуют сноскам из источника; номера примечаний обозначаются цифрами со звездочкой, например $-1 *$.

\section{СПИСОК ЛИТЕРАТУРЫ}

Cassirer E. (1991) Das Erkenntnisproblem in der Philosophie und Wissenschaft der neueren Zeit. 4 Bde. Bd. 3: Die nachkantischen Systeme. Darmstadt: Wissenschaftliche Buchgesellschaft (Первое издание: Berlin: Bruno Cassirer, 1920). 
Jacobi F. H. (1801) «Über das Unternehmen des Kritizismus die Vernunft zu Verstande zu bringen und der Philosophie überhaupt eine neue Absicht zu geben». Beyträge zur leichtern Uebersicht des Zustandes der Philosophie beym Anfange des 19. Jahrhunderts. Hrsg. von K. L. Reinhold. Heft 3. S. 1-110.

Jacobi F. H. (1816) «Über das Unternehmen des Kritizismus die Vernunft zu Verstande zu bringen und der Philosophie überhaupt eine neue Absicht zu geben». Friedrich Heinrich Jacobi's Werke. Bd. III. Leipzig: Gerhard Fleischer. S. 59-195.

Jacobi F. H. (1998) Werke. Gesamtausgabe. Hrsg. von K. Hammacher, W. Jaeschke. Bd. 1.1. Schriften zum Spinozastreit. Hrsg. von K. Hammacher, I.-M. Piske. Hamburg: Felix Meiner Verlag; Stuttgart - Bad Cannstatt: Friedrich Frommann Verlag (Günter Holzboog).

Jacobi F. H. (2004a) Werke. Gesamtausgabe. Hrsg. von K. Hammacher, W. Jaeschke. Bd. 2.1. Schriften zum Transzendentalen Idealismus. Unter Mitarbeit von C. Goetzki hrsg. von W. Jaeschke, I.-M. Piske. Hamburg: Felix Meiner Verlag; Stuttgart - Bad Cannstatt: Friedrich Frommann Verlag (Günter Holzboog).

Jacobi F. H. (2004b) Werke. Gesamtausgabe. Hrsg. von K. Hammacher, W. Jaeschke. Bd. 2.2. Schriften zum Transzendentalen Idealismus. Anhang. Unter Mitarbeit von C. Goetzki hrsg. von W. Jaeschke, I.-M. Piske. Hamburg: Felix Meiner Verlag; Stuttgart - Bad Cannstatt: Friedrich Frommann Verlag (Günter Holzboog).

Jaeschke W., Arndt A. (2012) Die klassische deutsche Philosophie nach Kant: Systeme der reinen Vernunft und ihre Kritik 1785-1845. München: C. H. Beck.

Ortlieb C. (2007) «Anstreichen, Durchstreichen. Das Schreiben in Büchern und die Philosophie der Revision bei Friedrich Heinrich Jacobi». Verbergen - Überschreiben - Zerreißen: Formen der Bücherzerstörung in Literatur, Kunst und Religion. Hrsg. von M. Körte, C. Ortlieb. Berlin: Erich Schmidt. S. 247-270.

Sandklauen B. (2000) Grund und Ursache. Die Vernunftkritik Jacobis. München: Wilhelm Fink Verlag.

Schopenhauer A. (1962) «Über die vierfache Wurzel des Satzes vom zureichenden Grunde. Eine philosophische Abhandlung». Schopenhauer A. Sämtliche Werke. Textkritisch bearbeitet und hrsg. von W. F. von Löhneysen. 5 Bde. Bd. 3: Kleinere Schriften. Darmstadt: Wissenschaftliche Buchgesellschaft. S. 7-89.

Schneider P.-P. (1986) Die "Denkbuecher» Friedrich Heinrich Jacobis. Stuttgart - Bad Cannstatt: Friedrich Frommann Verlag (Günter Holzboog) (Spekulation und Erfahrung. Texte und Untersuchungen zum Deutschen Idealismus. Abt. 2. Untersuchungen. Bd. 3).

Гаман И. Г., Якоби Ф. Г. (2006) Философия чувства и веры. Сост., вступ. ст., пер. с нем., прилож., коммент., примеч.: С. В. Волжин. СПб.: ПИЯФ РАН им. Б. П. Константинова. 


\title{
FRIEDRICH JACOBI AND IMMANUEL KANT: THE METACRITICISM OF THE NIHILISM OF THE PURE REASON
}

\author{
Sergei Volzhin
}

PhD in Philosophy, Associate Research Fellow at the Sociological institute of the Federal Center of Theoretical and Applied Sociology of the Russian Academy of Sciences.

Address: 25/14 7-ya Krasnoarmeyskaya str., St. Petersburg 190005, Russia.

E-mail: sergey.volzhin@gmail.com

KEYWORDS: Immanuel Kant, Friedrich Heinrich Jacobi, philosophy of belief, critical philosophy, transcendental philosophy, epistemology.

The article studies the philosophical strategy of Friedrich Jacobi's interpretation and criticism of Kant's critical philosophy, which allows to reveal better not only the specifics of the argumentation Jacobi directed against the one-sidedness of Kantian epistemology, but also to deeper understand the very nature and structure of the argumentative basis of Kant's theoretical philosophy as well as to clarify the internal contradictions of Kant's model of transcendental philosophy.

In the published essay "On the Attempt of Criticism to reduce Reason to the Understanding and to give a new Direction to Philosophy generally" ("Über das Unternehmen des Criticismus die Vernunft zu Verstande zu bringen und der Philosophie überhaupt neue Absicht zu geben") (1801), Jacobi seeks to uncover all the consequences of the contradictions arising in the theory of Kant's knowledge due to uncertainty of the status of the thing-in-itself. Jacobi argues that in the "Critique of Pure Reason", which should have explained the possibility of synthetic proposition a priori, Kant does not examine the possibility of an a priori antithesis: the manifold that is to be synthesized is only empirically presupposed by Kant. An analysis of Kant's theory of knowledge leads Jacobi to thesis: the reason is reduced by Kant to understanding, which is correlated through the imagination with sensibility, which depends on the imagination as an capacity of a priori contemplation. The productive and reproductive functions of the imagination should, as by Kant, ensure the constitution of the object of cognition and the reproduction of it as a representation. But since in the "Critique of Pure Reason", Kant does not indicate the conditions for the self-distinction of pure space, time and consciousness, Jacobi states that with the premise of the pure as continuous, equal to himself and indefinite, it is impossible to achieve a pure difference, a pure multitude, and to come from them to definitiveness: the question of the possibility of a priori synthetic proposition is not solvable, since the very possibility of synthesis is inexplicable. According to Jacobi, Kant's theory of knowledge could explain the possibility of cognition only in one case: proceeding from the activity of the power of imagination in its genesis from the blind (sensual) to the sighted (intellectual) capasity of the soul; but the internal contradictions of the foundations of the Kantian theory of knowledge disclosed by Jacobi have lead him to the conclusion that nihilism and solipsism are inevitable consequences of this theory. In his argument represented in this work, Jacobi appeared one of the first to point out the fundamental character of the concept of time in the Kantian system.

\section{REFERENCES}

Cassirer E. (1991) Das Erkenntnisproblem in der Philosophie und Wissenschaft der neueren Zeit. 4 Bde. Bd. 3: Die nachkantischen Systeme. Darmstadt: Wissenschaftliche Buchgesellschaft (First edition: Berlin: Bruno Cassirer, 1920).

Hamann J. G., Jacobi F. H. (2006) Filosofiya chuvstva i very [Philosophy of Feeling and Faith] (ed., tr., intr., suppl., comment., notes by S. V. Volzhin). St. Petersburg: PNPI RAS im. B. P. Konstantinova. (in Russian).

Jacobi F. H. (1801) "Über das Unternehmen des Kritizismus die Vernunft zu Verstande zu bringen und der Philosophie überhaupt eine neue Absicht zu geben". Beyträge zur leichtern Uebersicht des Zustandes der Philosophie beym Anfange des 19. Jahrhunderts (hg. v. K. L. Reinhold). Heft 3: 1-110. 
Jacobi F. H. (1816) “Über das Unternehmen des Kritizismus die Vernunft zu Verstande zu bringen und der Philosophie überhaupt eine neue Absicht zu geben". Friedrich Heinrich Jacobi's Werke. Bd. III. Leipzig: Gerhard Fleischer: 59-195.

Jacobi F. H. (1998) Werke. Gesamtausgabe (hg. v. K. Hammacher, W. Jaeschke). Bd. 1.1. Schriften zum Spinozastreit (hg. v. K. Hammacher, I.-M. Piske). Hamburg: Felix Meiner Verlag; Stuttgart- Bad Cannstatt: Friedrich Frommann Verlag (Günter Holzboog).

Jacobi F. H. (2004a) Werke. Gesamtausgabe (hg. v. K. Hammacher, W. Jaeschke). Bd. 2.1. Schriften zum Transzendentalen Idealismus (hg. v. C. Goetzki, W. Jaeschke, I.-M. Piske). Hamburg: Felix Meiner Verlag; Stuttgart - Bad Cannstatt: Friedrich Frommann Verlag (Günter Holzboog).

Jacobi F. H. (2004b) Werke. Gesamtausgabe (hg. v. K. Hammacher, W. Jaeschke). Bd. 2.2. Schriften zum Transzendentalen Idealismus. Anhang (hg. v. C. Goetzki, W. Jaeschke, I.-M. Piske). Hamburg: Felix Meiner Verlag; Stuttgart - Bad Cannstatt: Friedrich Frommann Verlag (Günter Holzboog).

Jaeschke W., Arndt A. (2012) Die klassische deutsche Philosophie nach Kant: Systeme der reinen Vernunft und ihre Kritik 1785-1845. München: C. H. Beck.

Ortlieb C. (2007) "Anstreichen, Durchstreichen. Das Schreiben in Büchern und die Philosophie der Revision bei Friedrich Heinrich Jacobi". Verbergen - Überschreiben - Zerreißen: Formen der Bücherzerstörung in Literatur, Kunst und Religion (hg. v. M. Körte, C. Ortlieb). Berlin: Erich Schmidt: 247-270.

Sandklauen B. (2000) Grund und Ursache. Die Vernunftkritik Jacobis. München: Wilhelm Fink Verlag.

Schopenhauer A. (1962) "Über die vierfache Wurzel des Satzes vom zureichenden Grunde. Eine philosophische Abhandlung". Schopenhauer A. Sämtliche Werke (textkritisch bearbeitet, hg. v. W. F. von Löhneysen). 5 Bde. Bd. 3: Kleinere Schriften. Darmstadt: Wissenschaftliche Buchgesellschaft: 7-89.

Schneider P.-P. (1986) Die "Denkbuecher" Friedrich Heinrich Jacobis. Stuttgart - Bad Cannstatt: Friedrich Frommann Verlag (Günter Holzboog) (Spekulation und Erfahrung. Texte und Untersuchungen zum Deutschen Idealismus. Abt. 2. Untersuchungen. Bd. 3).

DOI: https://doi.org/10.31119/essephts.2019.4.1.5

ESSE: Studies in Philosophy and Theology. Vol. 4. No. 1. 2019. P. 184-199.

(c) Sergei Volzhin, 2019 